\title{
Teacher trainers' and trainee teachers' understanding towards the curriculum philosophy regarding soft skills embedment in the Malaysian Institute of Teacher Education
}

\begin{abstract}
The embedment of soft skills into education programs in higher education is closely related to the curriculum philosophy brought by the respective institutions. The soft skills are embedded through understanding belief systems and practices among the teacher trainers. Furthermore it provides an insight into the curriculum philosophy on how to implement soft skills embedment. Therefore, this study aimed to understand teacher trainers' understanding and teaching practice in embedding soft skills while teaching core courses for the Bachelor of Teaching Program (PISMP) at the Malaysia Institute of Teacher Education (IPG). This understanding is necessary in order to resolve the misunderstanding that embedding soft skills are burdensome for the teacher trainers and that it is only documented without being practiced. The case study methodology was used through a qualitative approach. Five teacher trainers with different backgrounds and teaching experience participated as respondents. The findings resulted in improved understanding on teacher trainers' understanding about soft skills embedment and how the actual process of embedding soft skills occurred. The results of this study allow those involved in the development of student-teachers' soft skills to generate ideas to develop models for soft skills embedment that are in line with the interpretation of PISMP soft skills.
\end{abstract}

Keyword: Teaching practice; Active teaching; Embedding soft skills; Transmission teaching; Facilitative teaching 